\title{
Significance of MUC1 and MUC2 mucin expression in colorectal cancer
}

Y Ajioka, L J Allison, J R Jass

\begin{abstract}
Aims-To compare the lineage specific distribution of MUC1 and MUC2 mucins in normal colorectal mucosa and adenocarcinoma and to identify pathological correlations.

Methods-Paraffin wax sections from 51 colorectal cancers were examined for the expression of MUC1 and MUC2, non-Oacetyl sialic acid and the carbohydrate epitopes $\mathrm{Le}^{\mathrm{x}}, \mathrm{Le}^{\mathrm{y}}$, sialosyl-Le $\mathrm{e}^{\mathrm{x}}$, sialosyl-Tn, and Tn using standard histochemical methods.

Results-MUC1, Le ${ }^{\mathrm{x}}$ and Le $\mathrm{y}^{\mathrm{y}}$ co-localised with columnar cell secretions, whereas MUC2, mild periodic acid Schiff and sialosyl-Tn co-localised with goblet cell mucin in both normal and malignant tissues. Sialosyl-Le ${ }^{x}$ and Tn were associated with both lineages. In normal tissues MUC1, Le ${ }^{x}$ and $\mathrm{Le}^{y}$ showed only trace expression by crypt base columnar cells. Cancers could be classified into four phenotypes (MUC2+/MUC1-, MUC2+I MUC1+, MUC2-IMUC1+, MUC2-I MUC1-). Particular phenotypes showed significant correlations with cancer type, lymph node spread and peritumoral lymphocytic infiltration and trends falling short of significance in relation to grade of differentiation and contiguous adenoma.

Conclusions-Classification of colorectal cancer by means of lineage specific function may be relevant to both pathogenesis and prognosis.

( Clin Pathol 1996;49:560-564)
\end{abstract}

Keywords: colorectal cancer, MUC1, MUC2, pathogenesis, prognosis.

Seven genes for the protein component of epithelial mucins have been cloned. ${ }^{12}$ Of these, MUC2, ${ }^{3}$ MUC $3,{ }^{4}$ and $\mathrm{MUC}^{5}$ are expressed by intestinal goblet cells, although MUC2 predominates within colorectal goblet cell mucin. ${ }^{6}$ Interesting relations between MUC2 expression and the pathogenesis of colorectal neoplasia have been suggested. ${ }^{7}$ MUC2 is expressed by adenomas and mucinous carcinomas. ${ }^{7}$ Down regulation of MUC2 is seen in nonmucinous adenocarcinomas arising within adenomas, whereas cancers considered to develop de novo do not express MUC2.

MUC1 codes for non-secretory, cell membrane associated glycoproteins expressed along the columnar cell apexes in a variety of glandular tissues. ${ }^{1}$ MUC1 is the apomucin for epithelial membrane antigen and related structures identified with monoclonal antibodies raised against the membrane component of human milk fat globules. ${ }^{8} 9 \mathrm{MUC} 1$ expression is up regulated in a variety of cancers, including $\AA$ colorectal cancer. ${ }^{10}$

Monoclonal antibodies have been raised $\vec{A}$ against the repetitive amino acid sequences specific to the various apomucins. ${ }^{11}$ Antibodies $\bar{\omega}$ directed against MUC1 bind to the glycosylated protein, but unmasking of the apomu-? cin through periodate oxidation enhances $\frac{\overrightarrow{0}}{0}$ immunoreactivity. ${ }^{12}$ Antibodies to MUC2 react iे only with the non-glycosylated apomucin, giv- Oू ing a characteristic perinuclear pattern of 0 immunolocalisation within goblet cells.

It has been suggested previously that MUC1 and MUC2 could be related to specific cell lineages within colorectal cancer, namely colum- $\vec{\varphi}$ nar cells and goblet cells, respectively. ${ }^{13}$ Mucinlike material within colorectal cancer would 0 therefore comprise MUC1, MUC2 or mixtures of both depending on lineage differentiation. It was further predicted that particular carbohydrate structures might be co-expressed $\mathbb{D}$ with MUC1 and MUC2 and that these would $\Rightarrow$ show characteristic patterns of localisation. $\frac{9}{3}$ Specifically, MUC1 and non-sialylated type 2 blood group substances $\left(\mathrm{Le}^{\mathrm{x}}\right.$ and $\mathrm{Le}^{\mathrm{y}}$ ) would be expressed within the glycocalyx of columnar cells, whereas MUC2 and sialylated blood? group structures-for example, sialosyl-Tn, would be related to extracellular material with the typical morphological characteristics of secretory mucin. ${ }^{13}$

The aim of this study was to confirm the putative lineage specific co-expression of the carbohydrate and protein components of epithelial glycoproteins and to investigate rela- o tions with pathological parameters relevant to $N$ type, grade and stage of colorectal cancer.

\section{Methods}

Representative samples of paraffin wax embed- $\stackrel{\oplus}{+}$ ded tissue were obtained from the files of $48 \frac{T}{0}$ patients treated consecutively for colorectal $\stackrel{\oplus}{\Phi}$ cancer in 1992 at Auckland Hospital. The $\frac{\rho}{8}$ material included three synchronous cancers $\propto$ giving a total of 51 blocks, 41 of which included normal mucosa. Contiguous ad- 8 enoma was present in eight samples. Sections, $4 \mu \mathrm{m}$ thick, were cut and mounted on poly-Llysine coated slides. These were stained with $?$ haematoxylin and eosin, mild periodic acid Schiff (PAS) (specific for non-O-acetyl sialic acid) $)^{14}$ and a series of monoclonal antibodies visualised by the stepwise addition of biotinylated anti-mouse antibody followed by Streptavidin-biotin peroxidase labelled com- 
plex (Dako, Glostrup, Denmark; Serotec, Oxford, UK) and finally development with diaminobenzidine.

The antibodies were directed against the following epitopes: MUC1 (MUSE11, undiluted supernatant ${ }^{12}$ ), MUC2 (CCP58, ascites, diluted 1 in $1000^{7}$ ), $\mathrm{Le}^{\mathrm{x}}$ or CD15 (CMRF7, ascites, diluted 1 in $\left.400^{15}\right)$, sialosyl-Le ${ }^{\mathrm{x}}(\mathrm{Km}$ 93, diluted 1 in 100 , Serotec), sialosyl-Tn (TKH2, diluted 1 in 100, Dako), and Tn (HbTn1, diluted 1 in 50, Dako). The epitope $\mathrm{Le}^{\mathrm{y}}$ was demonstrated by means of the biotinylated lectin Ulex europaeus agglutinin-1 (UEA-1) (Sigma, Poole, Dorset, UK) at a dilution of 20 $\mu \mathrm{g} / \mathrm{ml}$ and visualised with the Streptavidinbiotin peroxidase labelled complex. Immunostaining for MUC1 was preceded by periodate oxidation. Known positive and negative tissue controls were included with each staining run.

The extent of each reaction was graded semiquantitatively as follows: $0,1=<5 \%$ of cells; $2=5-30 \%$ of cells; $3=30-60 \%$ of cells; $4=>60 \%$ of cells. These scores were used to demonstrate correlations between protein (MUC1 and MUC2) and carbohydrate markers by means of the Kendall rank coefficient. For the purposes of relating $\mathrm{MUC1}$ and MUC2 reactivity with pathological variables, cancers were regarded as positive when the score was at least 3 . On this basis, cancers were classified as MUC2+/MUC1-, MUC2+/ MUC1+, MUC2-/MUC1+, and MUC2-/ MUC1-. These phenotypes were related to a comprehensive set of clinical and pathological variables $^{16}$ and statistical analysis was performed by the $\chi^{2}$ test or Fisher's test, as appropriate, comparing the index phenotype with the rest.

\section{Results}

In normal mucosa MUC1 was observed along the apical membrane of crypt base cells (fig 1). This was a consistent finding, but was not observed without the unmasking effect of periodate oxidation. Of 51 cancers, $38(74.5 \%)$ showed obvious MUC1 up regulation (score 3-4), evident with or without periodate oxidation. MUC1 was expressed intraluminally, within the glycocalyx (fig 2) and in intracytoplasmic lumina. The intraluminal material was dense, eosinophilic and admixed with necrotic debris. It was variably mild PAS positive. Le ${ }^{x}$, Le $^{y}$ (UEA-1) and sialosyl-Le ${ }^{x}$ showed similar, but not identical patterns of distribution. In normal mucosa, $\mathrm{Le}^{\mathrm{x}}$ was expressed within the apical cytoplasm of crypt base columnar cells, whereas $\mathrm{Le}^{y}$ was observed in the glycocalyx (like MUC1). Crypt base expression of sialosyl-Le $e^{x}$ occurred rarely, focally and limited to the mucosa immediately adjacent to cancer. Superficially located goblet cells were occasionally noted to express sialosyl-Le $e^{\mathrm{x}}$. Expression of all three markers was up regulated in colorectal cancer. $\mathrm{Le}^{\mathrm{x}}$ and $\mathrm{Le}^{\mathrm{y}}$ were localised similarly to MUC1, though $\mathrm{Le}^{\mathrm{x}}$ also showed cytoplasmic staining. Not all MUC1 positive cancers expressed $\mathrm{Le}^{\mathrm{x}}$. Sialosyl-Le $\mathrm{L}^{\mathrm{x}}$ expression was more extensive, including material with the morphological characteristics of extracellu-

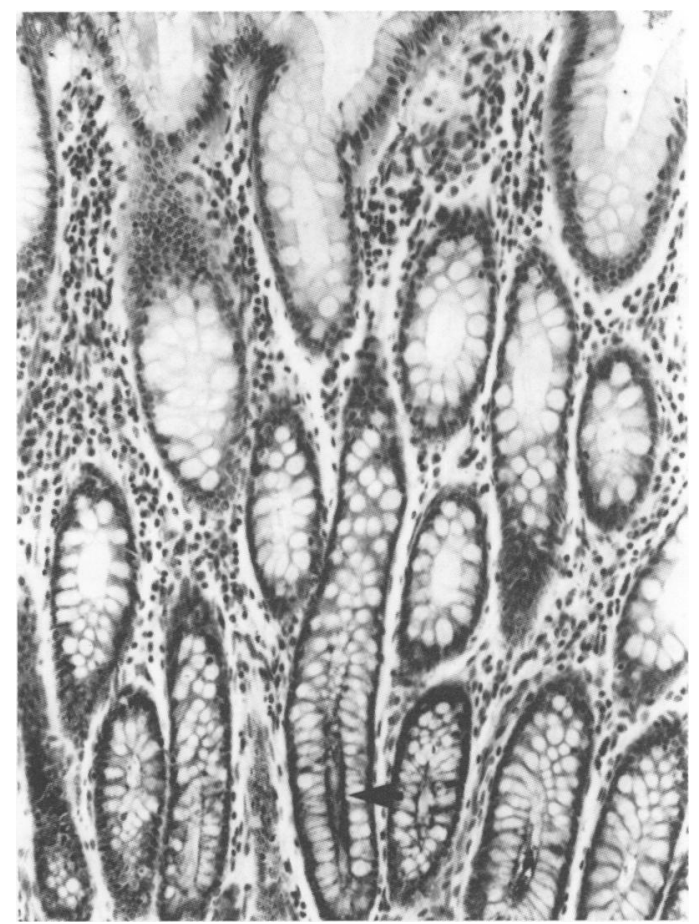

Figure 1 MUC1 expression within the glycocalyx of crypt base columnar cells (arrow). Immunoperoxidase with MUSE11.

lar mucin, as well as the glycocalyceal pattern described for MUC1, $\mathrm{Le}^{\mathrm{x}}$ and $\mathrm{Le}^{\mathrm{y}}$.

MUC2 was demonstrated in the perinuclear cytoplasm of normal and malignant goblet cells (figs 3 and 4). Of 51 cancers, $24(47.0 \%)$ had a MUC2 score of 3 or more. MUC2 was not evident in either the goblet cell theca or extracellular mucin. In cancers, MUC2 expression was associated with the presence of lumi-

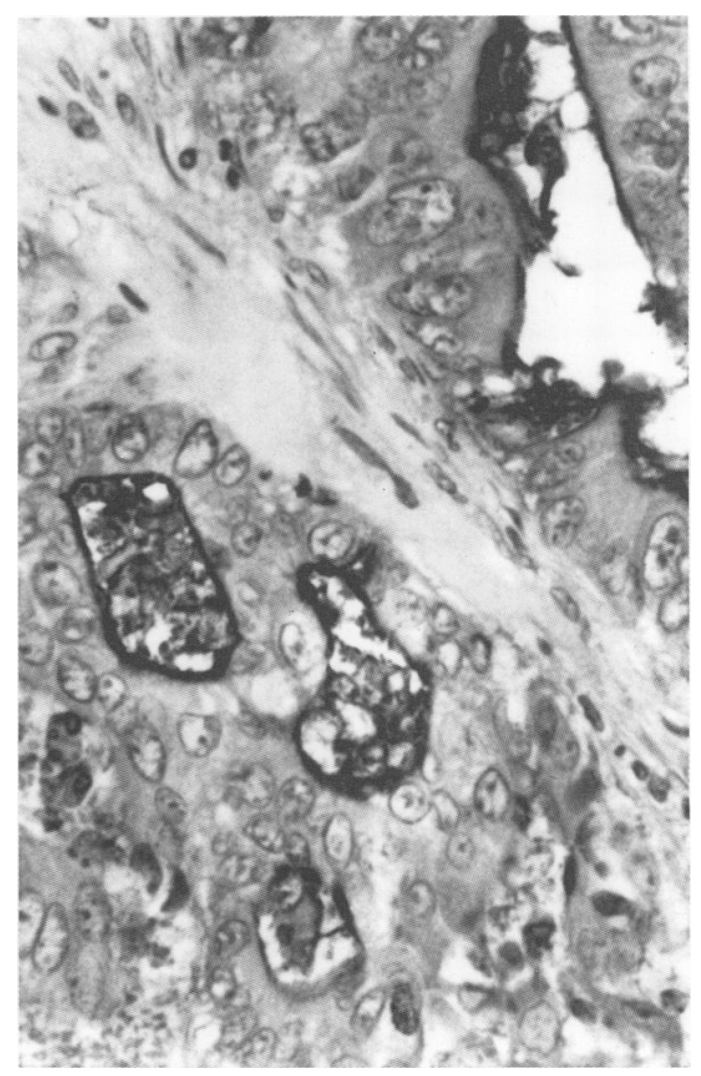

Figure 2 MUC1 expression within the glycocalyx of moderately differentiated adenocarcinoma. Immunoperoxidase with MUSE11. 
Table 1 Relations between MUC phenotypes and pathological variables

\begin{tabular}{|c|c|c|c|c|}
\hline & $M U C 2+/ M U C 1-$ & $M U C 2+/ M U C 1+$ & $M U C 2-/ M U C 1+$ & MUC2-IMUC1- \\
\hline Number (\%) & $9(17.6 \%)$ & $15(29.4 \%)$ & $23(45.1 \%)$ & $4(7.8 \%)$ \\
\hline \multicolumn{5}{|l|}{ Sex } \\
\hline Male & $4(44.4 \%)$ & $7(46.7 \%)$ & $10(43.5 \%)$ & $2(50.0 \%)$ \\
\hline Female & $5(55.6 \%)$ & $8(53.3 \%)$ & $13(56.5 \%)$ & $2(50.0 \%)$ \\
\hline Age (years) & $66.8 \pm 16.5$ & $68.9 \pm 12.6$ & $68.4 \pm 9.8$ & $65.0 \pm 9.8$ \\
\hline \multicolumn{5}{|l|}{ Site } \\
\hline Right colon & $2(22.2 \%)$ & $5(33.3 \%)$ & $9(39.1 \%)$ & $1(25.0 \%)$ \\
\hline Left colon & $5(55.6 \%)$ & $4(26.7 \%)$ & $10(43.5 \%)$ & $3(75.0 \%)$ \\
\hline Rectum & $2(22.2 \%)$ & $6(40.0 \%)$ & $4(17.4 \%)$ & $0(0 \%)$ \\
\hline \multicolumn{5}{|l|}{ Spread } \\
\hline Intramural & $2(22.2 \%)$ & $1(6.7 \%)$ & $3(13 \%)$ & $0(0 \%)$ \\
\hline Extramural & $7(77.8 \%)$ & $14(93.3 \%)$ & $20(87 \%)$ & $4(100 \%)$ \\
\hline \multicolumn{5}{|c|}{ Lymph node spread } \\
\hline Yes & $1(11.1 \%)^{\star}$ & $7(46.7 \%)$ & $12(52.2 \%)$ & $4(100 \%)$ \\
\hline No & $8(88.9 \%)$ & $8(53.3 \%)$ & $11(47.8 \%)$ & $0(0 \%)$ \\
\hline \multicolumn{5}{|l|}{ Grade } \\
\hline Well & $0(0 \%)$ & $1(6.7 \%)$ & $4(17.4 \%)$ & $0(0 \%)$ \\
\hline Moderate & $9(100 \%)$ & $11(73.3 \%)$ & $12(52.2 \%)$ & $3(75.0 \%)$ \\
\hline Poor & $0(0 \%)$ & $3(20.0 \%)$ & $7(30.4 \%)$ & $1(25.0 \%)$ \\
\hline \multicolumn{5}{|c|}{ Mucinous cancer } \\
\hline Yes & $1(11.1 \%)$ & $4(26.7 \%)^{\star}$ & $0(0 \%)$ & $0(0 \%)$ \\
\hline No & $8(88.9 \%)$ & $11(73.3 \%)$ & $23(100 \%)$ & $4(100 \%)$ \\
\hline \multicolumn{5}{|l|}{ Expanding } \\
\hline Yes & $6(66.7 \%)$ & $12(80.0 \%)$ & $17(73.9 \%)$ & $2(50.0 \%)$ \\
\hline No & $3(33.3 \%)$ & $3(20.0 \%)$ & $6(26.1 \%)$ & $2(50.0 \%)$ \\
\hline \multicolumn{5}{|l|}{ Lymphocytes } \\
\hline Yes & $1(11.1 \%)$ & $2(13.3 \%)$ & $8(34.8 \%)^{\star}$ & $0(0 \%)$ \\
\hline No & $8(88.9 \%)$ & $13(86.7 \%)$ & $15(65.2 \%)$ & $4(100 \%)$ \\
\hline \multicolumn{5}{|c|}{ Residual adenoma } \\
\hline Positive & $1(11.1 \%)$ & $4(26.7 \%)$ & $3(13.0 \%)$ & $0(0 \%)$ \\
\hline Negative & $8(88.9 \%)$ & $11(73.3 \%)$ & $20(87.0 \%)$ & $4(100 \%)$ \\
\hline \multicolumn{5}{|l|}{ Jass group } \\
\hline 1 & $2(22.2 \%)$ & $2(13.3 \%)$ & $8(34.8 \%)$ & $0(0 \%)$ \\
\hline 2 & $3(33.3 \%)$ & $7(46.7 \%)$ & $2(8.7 \%)$ & $0(0 \%)$ \\
\hline 3 & $4(44.4 \%)$ & $3(20.0 \%)$ & $7(30.4 \%)$ & $2(50.0 \%)$ \\
\hline 4 & $0(0 \%)$ & $3(20.0 \%)$ & $6(26.1 \%)$ & $2(50.0 \%)$ \\
\hline
\end{tabular}

${ }^{\star} \mathrm{p}<0.05$ (Fisher's exact test).

nal and interstitial material having the features of secretory mucin: lightly basophilic on staining with haematoxylin and eosin and foamy or

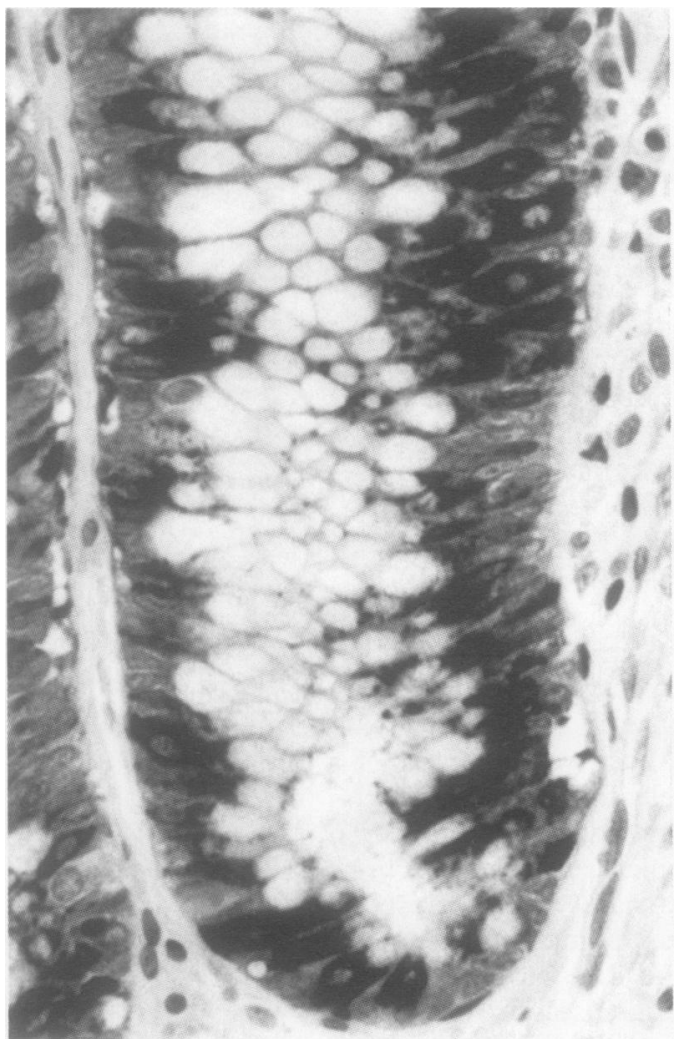

Figure 3 MUC2 expression within normal colon showing restriction of expression to the perinuclear cytoplasm of goblet cells. Immunoperoxidase with CCP58. wispy. The same material was mild PAS positive and expressed both sialosyl-Tn and $\stackrel{\mathbb{Q}}{\circ}$ sialosyl-Le ${ }^{x}$.

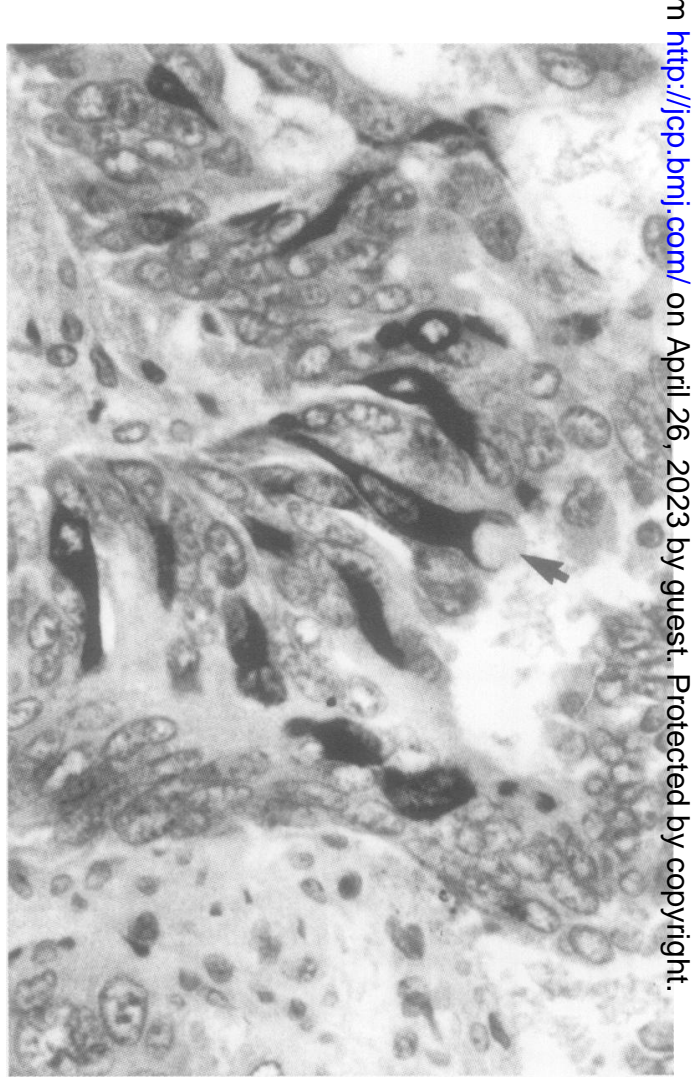

Figure 4 MUC2 expression within moderately differentiated colorectal cancer limited to the perinuclear cytoplasm of cells of goblet lineage. The goblet cell theca (arrow) is unstained. Immunoperoxidase with CCP58. 
Tn expression was either cytoplasmic when it was associated with MUC1 or within the Golgi zone in areas of MUC2 positivity. Glycocalyceal and intraluminal $\mathrm{Tn}$ was infrequent. Scores for MUC1 showed significant positive correlations with scores for $\mathrm{Le}^{y}$ and cytoplasmic Tn and a significant negative correlation with mild PAS. Scores for MUC2 showed a significant positive correlation with mild PAS, sialosyl-Tn and Golgi zone $\mathrm{Tn}$, and a significant negative correlation with $\mathrm{Le}^{y}$ (Kendall rank coefficients not shown). Sialosyl-Le $\mathrm{e}^{\mathrm{x}}$ scores did not correlate with either MUC1 or MUC2, being strongly coexpressed with both. Despite their similar patterns of immunolocalisation in normal and malignant tissues, scores for MUC1 and $\mathrm{Le}^{\mathrm{x}}$ did not show a significant correlation. MUC1 and MUC2 scores showed a significant negative correlation. Relations between MUC1/MUC2 phenotypes and pathological data are shown in table 1.

\section{Discussion}

It would seem reasonable to assume that the normal counterpart of secretory material within colorectal cancers is goblet cell mucin, or principally MUC2 mucin. Yet, this is true only for a subset of cancers, of which mucinous adenocarcinoma would be an obvious example. This study indicates that non-mucin-like intraluminal secretions, glycocalyceal material and the mucins of intracytoplasmic lumina are up regulated, membrane associated glycoproteins coded for by MUC1. The normal counterpart is the trace secretion associated with the apical cytoplasm and glycocalyx of crypt base columnar cells. The existence of such a population of secretory columnar cells has been known for many years through ultrastructural studies, the cells being termed differentiating cells, ${ }^{17}$ intermediate cells ${ }^{18}$ and, in species other than humans, vacuolated columnar cells. ${ }^{19}$ This is the first description of MUC1 immunolocalisation along the apical membrane of these cells (fig 1), although biochemical studies have confirmed the presence of MUC1 in normal colorectal mucosa. ${ }^{20}$ Demonstration of MUC1 within colorectal cancers (fig 2) did not require pretreatment with periodic acid, perhaps because the apomucin is less heavily glycosylated as well as up regulated. Recapitulation of coexpressed MUC1, Le $e^{\mathrm{x}}$ and $\mathrm{Le}^{\mathrm{y}}$ within crypt base columnar cells by malignant columnar cells indicates a histogenetic link between these populations. Sialosyl-Le $\mathrm{e}^{\mathrm{x}}$ is known to be coexpressed with MUC1 in tumours, but not in normal mucosa ${ }^{20}$; this could arise through abnormal sialylation of $\mathrm{Le}^{\mathrm{x}}$. As the precursor of core structure $3,{ }^{13}$ Tn would be expected to co-localise with all classes of glycoprotein.

MUC2 expressing cells (fig 4) were conspicuous in $47 \%$ of cancers, sometimes in association with MUC1 cells (table 1). MUC2 scores were higher when there was MUC1 up regulation. Coexpression of MUC2 with sialosyl-Tn and sialosyl-Le $e^{\mathrm{x}}$ is consistent with previous reports. ${ }^{21-23}$

Grouping the cancers into the four possible phenotypes, a number of interesting trends, some of statistical significance, emerged. The lack of a significant association with grade of differentiation is of interest given the fact that lineage differentiation must account for the different MUC phenotypes. The pattern closest to normal (MUC2+/MUC1-) occurred in nine cancers, of which only one was associated with lymph node metastases (Fisher's exact test, $\mathrm{p}=0.019)$. Others have demonstrated the converse relation between MUC1 up regulation and cancer spread. ${ }^{24}$ The phenotype MUC2+/MUC1+ included four of the five mucinous cancers (the other being MUC2+/ MUC1-) (Fisher's exact test, $p=0.02$ ). It is possible that hypersecretion of all mucin species (perhaps including MUC3 and MUC4) is a characteristic of mucinous carcinoma. There was a trend for residual adenoma (tubulovillous and villous) to be associated with MUC2+/MUC1 + cancers (Fisher's exact test, $p=0.16$ ). This fits not only with the high frequency of MUC2 expression in mucinous carcinomas, but with their histogenetic relation to villous adenomas. ${ }^{7}$ It remains to be shown whether a proportion of MUC2- cancers are of de novo origin. ${ }^{7}$ In this regard, the histogenetic link between normal crypt base columnar cells and MUC1+ cancers (see earlier) is of potential interest. Could de novo cancers arise directly from this population of immature columnar cells?

The association between peritumoral lymphocytic infiltration and MUC2-/MUC1+ cancers (Fisher's exact test, $p=0.04$ ) could be due to removal of the immunosuppressant effect of MUC2 mucus. MUC2 mucins bear the sialosyl-Tn antigen which is known to mediate the inhibition of natural killer cell cytotoxicity. ${ }^{25}$ Furthermore, the fact that the MUC1 antigen (when expressed by tumours) is recognised by cytotoxic $T$ cells could be relevant to this finding also. ${ }^{26}$ The MUC2-/ MUC1 + cancers were unusual in being mainly distributed in Jass group 1 (those with a pronounced lymphocytic infiltrate) or Jass groups 3 and 4 (poor prognostic groups). ${ }^{16}$

Whilst peripheral to the molecular changes fundamental to the process of oncogenesis, the characterisation of colorectal cancer mucin provides new opportunities for marking different cell lineages and developing classifications that may be relevant to the pathogenesis and behaviour of colorectal cancer.

We thank DrY Hinoda, Dr I F C McKenzie and Dr D N J Har for their gifts of MUSE11, CCP58 and CMRF7 monoclona antibodies, respectively, and Ms L White-Johnson for secretaria support.

1 Gum JR. Mucin genes and the proteins they encode: structure, diversity, and regulation. Am $\mathcal{f}$ Respir Cell Mol Biol ture, diversity,

2 Jass JR, Roberton AM. Colorectal mucin histochemistry in health and disease: A critical review. Pathol Int 1994 44:487-504.

3 Toribara NW, Gum JR, Culhane PJ, Lagace RE, Hicks JW, Petersen GM, et al. MUC-2 human small intestinal mucin gene structure. Repeated arrays and polymorphism. $\mathcal{F}$ Clin Invest 1991;88:1005-13.

4 Chang S-K, Dohrman AF, Basbaum CB, Ho SB, Tsuda T Toribara NW, et al. Localization of mucin (MUC2 and MUC3) messenger RNA and peptide expression in MUC3) messenger RNA and peptide expression in
human normal intestine and colon cancer. Gastroenterology

5 Ogata S, Uehara H, Chen A, Itzkowitz SH. Mucin gene expression in colonic tissues and cell lines. Cancer Re 1992;52:5971-8. 
6 Tytgat KMAJ, Büller HA, Opdam FJM, Kim YS, Einerhand AWC, Dekker J. Biosynthesis of human colonic mucin MUC2 is the prominent secretory mucin. Gastroenterology 1994;107:1352-63.

7 Blank M, Klussmann E, Kruger-Krasagakes S, SchmittGraff A, Stolte M, Bornhoeft G, et al. Expression of MUC2-mucin in colorectal adenomas and carcinomas of different histological types. Int $\mathcal{f}$ Cancer 1994;59:301-6.

8 Burchell J, Gendler S, Taylor-Papadimitriou J, Girling A, Lewis A, Millis R, et al. Development and characterization of breast cancer reactive monoclonal antibodies directed of breast cancer reactive monoclonal antibodies directed to the core protein

9 Gendler SJ, Lancaster CA, Taylor-Papadimitriou J, Duhig $\mathrm{T}$, Peat N, Burchell J, et al. Molecular cloning and expression of human tumour associated polymorphic epithelial mucin. F Biol Chem 1990;265:15286-93.

10 Zotter S, Lossnitzer A, Hageman PC, Delemarre JFM Hilkens J, Hilgers J. Immunohistochemical localization of the epithelial marker MAM-6 in invasive malignancies and highly dysplastic adenomas of the large intestine. Lab Invest 1987;57:193-9.

11 Carrato C, Balague C, De Bolos C, Gonzalex E, Gambus G Planas J, et al. Differential apomucin expression in norma and neoplastic human gastrointestinal tissues. Gastroenter ology 1994;107:160-72

12 Ohe Y, Hinoda Y, Irimura T, Imai K, Yachi A. Expression of sulfated carbohydrate chains detected by monoclonal antibody $91.9 \mathrm{H}$ in human gastric cancer tissues. Fpn $\mathcal{F}$ Cancer Res 1994;85:400-8.

13 Jass JR, Allison LJ, Edgar SG. Distribution of sialosyl Tn and Tn antigens within normal and malignant colorectal epithelium. F Pathol 1995;176:143-9.

14 Veh RW, Meessen D, Kuntz D, May B. In: Malt RA, Williamson RCN, eds. Colonic carcinogenesis. Lancaster: Williamson RCN, eds. Colonic
MTP Press Ltd, 1982:355-65.

15 Davidson SE, McKenzie JL, Beard MEJ, Hart DNJ. The tissue distribution of the $3 \alpha$-fucosyl-N-acetyl lactosamin determinant recognized by the CD15 monoclonal antibodies CMRF-7 and 27. Pathology 1988;20:24-31

16 Jass JR, Morson BC. Reporting colorectal cancer. 7 Clin Pathol 1987;40:1016-23.
17 Lorenzsonn V, Trier JS. The fine structure of human rectal mucosa. The epithelial lining of the base of the crypt. Gastroenterology 1968;55:88-100

18 Kaye GI, Fenoglio CM, Pascal LRR, Lane N. Comparative electron microscopic features of normal, hyperplastic and adenomatous human colonic epithelium. Gastroenterology 1973;64:926-45.

19 Chang WWL, Leblond CP. Renewal of the epithelium in the descending colon of the mouse. I: Presence of three cell populations: vacuolated-columnar, mucous and argentaffin. Am ₹ Anat 1971;131:73-100.

20 Hanski C, Drechsler K, Hanisch FG, Sheehan J, Manske M Okorek D, et al. Altered glycosylation of the MUC-1 protein core contributes to the colon carcinoma-associated increase of mucin-bound sialyl-Lewis ${ }^{x}$ expression. Cancer Res 1993;53:4082-8.

21 Itzkowitz SH, Bloom EJ, Lau T-S, Kim YS. Mucin associated $\mathrm{Tn}$ and sialosyl-Tn antigen expression in colorectal polyps. Gut 1992;33:518-23

22 Ogata S, Ho I, Chen A, Dubois D, Maklansky J, Singhal A, et al. Tumor-associated sialylated antigens are constitutively expressed in normal human colonic mucosa. Cancer Res 1995;55:1869-74.

23 Hanski C, Hanski ML, Zimmer T, Ogorek D, Devine P, Riecken EO. Characterization of the major sialyl-Le(X)positive mucins present in colon, colon carcinoma, and sera of patients with colorectal cancer. Cancer Res 1995;55:928-33.

24 Nakamori S, Ota DM, Cleary KR, Shirotani K, Irimura T. MUC1 mucin expression as a marker of progression and metastasis of human colorectal carcinoma. Gastroenterology 1994;106:353-61.

25 Ogata S, Maimonis PJ, Itzkowitz SH. Mucins bearing the cancer-associated sialosyl-Tn antigen mediate inhibition of natural killer cell cytotoxicity. Cancer Res 1992; of natural killer cell cytotoxicity. Cancer Res 1992; on

26 Jerome KR, Brand DL, Bendt KM, Boyer CM, TaylorPapadimitriou J, McKenzie IFC, et al. Cytotoxic T-lymphocytes derived from patients with breast adenocarcinoma recognize an epitope present on the protein core of a mucin molecule preferentially expressed by malignant cells. Cancer Res 1991;51:2908-16. 